\title{
Study on the Promotion, Management and Maintenance of Domestic Ceramic Brands in China
}

\author{
Huiwen Li \\ School of Ceramic Art \\ Jingdezhen Ceramic Institute \\ Jingdezhen, China
}

\begin{abstract}
Developing brand is the only way for China's ceramic industry. This paper starts with the promotion, management and maintenance of brands to briefly explain the problems that should be paid attention to in developing domestic ceramic brands.
\end{abstract}

Keywords-domestic ceramic; brand promotion; management; maintenance

\section{INTRODUCTION}

Domestic ceramics industry in China has long been constrained by the thinking of "wining by quantity to exchange by export", and focus on the production cycle. Many companies survive relying on OEM production of products of developed countries, lacking brand awareness, and some enterprises are even willing to earn only small profits by OEM to avoid risks, which is extremely unfavorable for the long-term and healthy development of enterprises and the domestic ceramic industry. In the context of continuously improved manufacturing level, developing brands has become the inevitable direction for ceramic industry in China to get out of low-cost competition status, win the market, and complete industrial upgrading as well as the realistic choice of more and more ceramic enterprises. Needless to say, it is an important symbol for ceramic enterprises to become normative, mature and healthy by transforming from simply producing products to making creating a brand systematically. However, many companies make the road of brand management deviated from the right direction out of the non-rational attitude of blindly following the trend and seeking quick success. After solving the problem of product design and technology, how to promote, manage and maintain the brand have become new problems in front of domestic ceramic enterprises.

\section{CORRECT BRAND AWARENESS AND PROMOTION METHODS}

A brand is an intangible asset that brings premiums and added value to owners, of which the carriers are the name, term, symbol, mark or design and its combination used to differentiate it from products or services of other competitors. Fundamentally, it is the core quality appeal and commitment of a product or service to consumers. It concentrates the quality, service and even culture of such service or product, which is a source of value added to the brand. Ceramic industry in China does not have an even understanding of the brand. In general, the architectural ceramics industry pays more attention to brand building, but there are some misunderstandings that the brands with "high grade and high price" are famous brands; They hold that the brand operation and management is the introduction of VI (visual identification system), upgrading product packaging, bombing advertisement; the degree of brand management of domestic ceramic enterprises is relatively low, since a considerable part of the domestic ceramic enterprises have not yet had the correct and clear brand awareness, which can be seen from the advertising of current domestic ceramics enterprises.

Domestic ceramics enterprises in China produce and deliver very few advertisements, so there is almost no influential domestic ceramic ad. There are only some simple promotional video specifically for business or brand products, fully reflecting the degree of weakness of current brand awareness of domestic ceramic industry. On the one hand, this is due to the backward consumption consciousness of domestic users of domestic ceramic. On the other hand, it also shows that domestic ceramic enterprises do not actively promote the relationship between ceramic culture, ceramic art and high-quality life and cultivate and develop potential markets in this way. At present, although the level of household consumption in China has greatly improved, people generally do not realize the significance of domestic ceramic to the quality of life. The consumer group who really understand domestic ceramic has not been formed yet. Many families' requirement for tableware and tea set is only for use, and even many consumers do not know that there are domestic ceramic sold in a complete set. Their domestic ceramic is incompatible with the overall home environment, which is in contrast with people's pursuit of excellence in details related to other quality of life such as home textiles and home furnishing. In developed countries, conditional families prepare several sets of exquisite tea utensils and tableware to meet the needs of different situations. In terms of cups, people generally think that English bone china should be used in drinking black tea, Italian demi-tasse should be used in drinking Italian coffee, mug should be used in drinking American coffee and glass should be used in drinking fruit juices and milk. It is considered as an impolite behavior lacking environmental protection concept to entertain guests with disposable cups. In addition to daily 
use, people have the habit of collecting porcelain from famous kilns. They display the exquisite ceramics in the living room as a symbol of their taste and worth. The formation of this consumption concept of domestic ceramic on the one hand results from some historical factors, on the other hand is related with the well-known international domestic ceramic brand sparing no effort to promote their own brand and culture, and shaping the culture of domestic ceramic. In Taiwan and other emerging ceramics market, beautiful ceramic advertising plays a huge role in consumer education and training. Based on the current status of the domestic industry, it is suggested that the Ceramics Industry Association and well-known enterprises in the industry take the lead in promoting and inspiring consumers so as to cultivate the domestic market for domestic ceramic.

\section{TO DEVELOP A REASONABLE BRAND MANAGEMENT STRATEGY}

The key content of ceramic brand management is the price policy and sales strategy. First of all, the price of product should be built on the basis of the perceived value of consumers, and we should make consumers think that the products are worth the money by improving product quality and service standards and reducing costs. The reason for ceramic industry in developed countries positioning at the high end is the high cost of raw materials, manpower, fuel, and equipment investment and so on apart from the design and brand factors. Relatively speaking, Chinese ceramics have obvious price advantage, which provides favorable conditions for diversified brand operation of Chinese domestic ceramic. However, in the actual market competition, some brands ignore the image and positioning, but only focus on the immediate petty profits, to behave harmfully to the core values of brand, such as imitation of other successful brand product design style and high pricing and then giving a high discount, etc. This behavior assimilate itself with other products, so it can only hover in the low-end product market, resulting in vicious competition in the market, which eventually leads to the deterioration of brand image and product prices and even leads to foreign antidumping complaints.

Apart from price policy, it also should configure a reasonable sales strategy and establish suitable brand sales channels. Limited by the deficiency of capital and management level, China's domestic ceramic enterprises marketing mainly use local agency sales system, and the sales channels are mainly local shopping malls, supermarkets, and groceries, etc. Except for ceramic industrial zones such as Jingdezhen and Tangshan, the franchise stores of domestic ceramic are extremely rare and the overall sales channel tends to be low end. On the one hand, this has led to the difficulty in selling high-quality ceramic products. The reason why some domestic ceramic products designed and manufactured by famous ceramic artists are almost always in the sales mode of art porcelain lies in this. On the other hand, consumers also have no access to high quality domestic ceramic products. At present, most domestic consumers can only buy domestic ceramic products in supermarkets, corner shops, grocery stores, and even stalls, and the relatively low product quality from these channels is far from satisfying consumers' needs. In addition, for domestic ceramic enterprises, it is difficult for the agency sales system to effectively grasp the market and sales conditions, and consumer feedback on the product is also difficult to convey in time. Thus, companies lose the direct and effective way to promote the product at the same time, which is extremely unfavorable for reproduction and redesign of enterprises. In the aspect of construction of sales channel, the practice of Huaguang ceramics in China has a certain guiding significance. Huaguang ceramic is high-end positioning, so it makes efforts to develop sales terminal building compatible with it. Brand image shops in high-end shopping malls of more than a dozen first-tier cities in China starting from the domestic market and built simultaneously in domestic and international market have reached nearly one hundred. In the international market, Huaguang Ceramics took the lead in making breakthroughs with its own brand identity and entered high-end department stores or home stores in Russia, the United States and Arab countries. The establishment of such sales terminals is bound to consolidate the status of high-end domestic ceramic in China.

\section{TO ATTACH IMPORTANCE TO USER EXPERIENCE AND MAINTAIN BRAND REPUTATION}

Paying attention to user experience is of great significance to the maintenance work of brand reputation, and attitude and ability of sales person is the key factor. The qualities of sales and service person of domestic ceramic brands in China are different, and types of services are mostly in sales and after-sales, which are mostly for group users or agent vendors but rarely for the retail customers directly. Thus, they lack brand experience for retail users. At the same time, there is also some difficulty in unified training for sales terminal personnel of domestic ceramic and the application of visual identification system of the shop. It is very difficult to play the role of publicizing the brand if the clerks improperly receive customers. The well-known foreign ceramics brands not only focus on in-sales and aftersales service, but also pay attention to pre-sales service. The enterprises include the issues concerned by consumers such as product design, production mode, production volume, application environment and supporting solutions into the service contents in ahead. They begin to consider to improve from the development stage of product, and training the sales persons in advance to make them not only get familiar with the history, idea, and features of the brand, but also can better introduce targeted products according to the needs of customers and provide customers with coordinated guiding service. In addition, successful pioneer brands tend to attract a large number of producers to imitate them, so enterprises should effectively monitor this and even resort to laws to safeguard brand equity and credibility. After the series of "Franz" ceramic products developed by Haichang Industry were put in the world market, the company gained good corporate reputation and business reputation and got population in public. As a result, many counterfeit products appeared in China before and after 2006, and Haichang employed lawyers brought them to court. When they effectively protect their own rights and the legal status of the 
brand, they also promote customer to trust in the brand, so as to be more loyal to Franz brand.

\section{CONCLUSION}

The brand management of domestic ceramic is a systematic project, so we must make all-round and in-depth integration of business philosophy, visual identification system, enterprise management system, technical equipment, and product positioning of domestic ceramic, maintain a good match, mutual complementation and mutual promotion, and maintain the stability of the brand image in order to promote the healthy development of the brand. It is also necessary to see that the construction and management of daily-use brands is the same to that of any other kind of product brand, which is a long-term process. The most famous international brands in the high-grade domestic ceramic market, such as Wedgewood, Roseitake, and Rozental all gradually accumulate the brand effect by sticking to the road of gentrification and high quality in long term. In the early stage of brand building, enterprises may face difficulties in actual operation due to the increase in expenses of promotion and terminal construction. However, the brandization is an inevitable choice for China's domestic ceramic industry. Building the brands as early as possible and maintaining the healthy development of brand have great significance to the enterprise itself as well as society and the country.

\section{REFERENCES}

[1] Li Qianru, Li Peiliang. Brand Marketing Methods. Guangdong Economy Press, 2002.4

[2] Ju Zhongtian. Brand Propagation. China Economy Press,2004.5.

[3] Xiao Zhong. The Way of Making Brand Popular. Economy Management Press, 1999.4

[4] Li Yanzu. The Concept of Art Design. Hubei Art Press,2002.3

[5] Zhen Xinan. The Dreamworks of Native Brand. Tsinghua University Press, 2004.9.

[6] Fei Mingsheng, Hao Yuanxiao. Marketing. South China University of Technology Press,2005,4.

[7] Huang Xinhong. Domestic Ceramic Industry Abroad in 2000, China Ceramic,1999,6.

[8] Li Yunchang. The State of the Domestic Ceramic and Development Strategy. Ceramic Engineering, 1995,6.

[9] Zhang Chun, $\mathrm{Hu}$ Xinle. The Cultivation Strategy of International Competitive Power for China Domestic Ceramic Industry. Fushan Ceramic. 2003,6.

[10] Xia Haiqing. The Study of China Ceramic Construction Brand Impression. China Ceramic Engineering.

[11] Guo Lihua. The Strategy of Making China Ceramic brand Popular All over the World. Operation and Management.2003,9.

[12] Zhang Xiqiu. The Strategy Rearrangement of Domestic Ceramic. Jiangsu Ceramic,2008,4

[13] Yan Huan. The Development Trend of Domestic Ceramic Design. China Ceramic.2009,2.

[14] Yang Qing. The Discussion of China Domestic Brand Construction. China Ceremic,2009,1.

[15] Xu hua, Qi Xia. The Improvement Approach of Jingdezhen Domestic Ceramic Enterprise. Jiangsu Ceramic,2005,4.

[16] Hong Liang. The Creative Industry and Creative Economy. Economic Vision.2006,10
[17] Wang Zhiguo. The Competitive Strategy Selection of Tianfu Domestic Ceramic Company Limited. Southwestern University of Finance and Economics. 2006

[18] Ma Luyue. Research on the Factors in Mixed Brand Strategy Influence on Consumer Evaluation of the Product. Shanghai Jiaotong University. 2007 